\title{
Full-scale finite element analysis of deformation and contact of a wire- wrapped fuel bundle subject to realistic thermal and irradiation conditions
}

\author{
X. Ye ${ }^{\mathrm{a}}, \mathrm{F} . \mathrm{Gao}^{\mathrm{b}}, \mathrm{X} . \mathrm{Chen}^{\mathrm{c}}, \mathrm{X} \cdot \mathrm{Liu}^{\mathrm{a}, *}$, Y.G. Wei ${ }^{\mathrm{d}}$ \\ ${ }^{\text {a }}$ State Key Lab. of Nonlinear Mechanics, Institute of Mechanics, Chinese Academy of Sciences, Beijing 100190, China \\ ${ }^{\mathrm{b}}$ China Institute of Atomic Energy, Beijing 102413, China \\ ${ }^{\mathrm{c}}$ School of Aerospace Engineering, Beijing Institute of Technology, Beijing 100081, China \\ ${ }^{\mathrm{d}}$ Department of Mechanics and Engineering Science, College of Engineering, Peking University, Beijing 100871, China
}

\section{A R T I C L E I N F O}

\section{Keywords:}

Bundle-duct interaction

Irradiation creep

Contact separation

Pin dispersion

Oval distortion

Irradiation swelling

\begin{abstract}
A B S T R A C T
The fuel bundle in a fast breeder reactor (FBR) is wrapped with wires for guiding the flow of liquid metal. Under operation condition with irradiation and high temperature, the wrapped bundle undergoes complex contact so that the flow channel of liquid will be affected. There are mainly four factors involved: radiation swelling, thermal expansion, radiation creep and thermal creep. In the present study, a full-scale finite element model (FEM) is established to consider the effect of these factors on the complex contact during operation. The established model can capture the contact separation, spacer wire's dispersion, oval distortion and bowing details of fuel pins. The results show that the local contact dispersion caused by the wire slip can alleviate the severe transverse bending deformation of the bundle. What is more important, we find out that the dispersion of contact points in the peripheral direction of the bundle is another key factor for alleviating the severe deformation of the bundle during operation, this new mechanism - peripheral dispersion of contact - has not been achieved in previous studies.
\end{abstract}

\section{Introduction}

Most of the large-scale fast breeder reactor (FBR) power stations were liquid metal fast breeder reactors (LMFBR) cooled by liquid sodium. The deformation of pin-to-pin channel or pin-to-duct channel is critical for the flow of liquid sodium. The bowing of bundle pins may reduce the clearance and further affect the exchange rate of heat between the pin and liquid sodium. When fuel burnup increases, the release of internal fission gas will cause void swelling and irradian creep of cladding, leading to the increase of fuel pin diameter (Shibahara et al., 1993; Maeda et al., 2005). Therefore, bundle-duct interaction (BDI) and pin-to-pin interaction are considered to be the major factors which affect the life of FBR fuel assemblies, and the deformations of fuel pins and ducts are investigated for the integrity evaluation of the fuel assemblies.

In the late 1990s, a computer code Marse (Itoh et al., 1994) has been developed to analyze structural behaviors of fast breeder reactor (FBR) fuel subassemblies under irradiation conditions. The contact between adjacent fuel pins is considered by using spring elements adopted at the contact points. This program provided the ability to treat the complex BDI condition (more than 105 contact pairs) with high accuracy and low computational cost.

Later, a three dimensional (3D) beam element model (BAMBOO) has been developed by Uwaba and Tanaka (2001) to analyze the wirewrapped fast breeder reactor (FBR) fuel pin bundle deformation under BDI. The fuel pin bowing and cladding oval distortion can be considered in the BAMBOO code. The BAMBOO (Uwaba and Tanaka, 2001) code has been successfully used to predict the pin-to-duct clearances in the out-of-pile compression test, and they conclude that the cladding oval distortion may reduce the bowing of the fuel pin. A dispersion model was introduced in the further version of BAMBOO (Uwaba et al., 2004; Uwaba et al., 2005), to account for the deviation of the wire position during irradiation swelling, creep, and thermal expansion.

The BAMBOO code was verified by the out-of-pile bundle compression test with large diameters $(8.5 \mathrm{~mm}$ and $10.4 \mathrm{~mm}$ ) (Uwaba et al., 2014), and the simulation results were in good agreement with the Computed Tomography (CT) image analysis for the pin-to-duct and pinto-pin clearances. BAMBOO also performs iterative calculations in conjunction with thermal-hydraulic analysis to achieve a balance between deformation and temperature (Uwaba et al., 2017).

In the past, numerical analysis of full-scale fuel pin bundle could not be achieved due to limitation of computational capability. From the

\footnotetext{
* Corresponding author.

E-mail address: xiaomingliu@lnm.imech.ac.cn (X. Liu).
} 
perspective of structure deformation, the previous BDI analysis codes (Itoh et al., 1994; Uwaba and Tanaka, 2001; Uwaba et al., 2004; Sakai et al., 1978) were based on the 3D beam model to study the pin-bowing effect. From the perspective of fluid flow pattern, the subchannel analysis codes (Chelemer et al., 1972; Sun et al., 2018; Shan et al., 2009) were developed to study thermo-hydraulic characteristics. Over the past half-century, computing capability has grown tremendously, and the dramatic increase in computing capability allows for the 3D simulation of the wire-wrapped fuel bundles. In the previous studies, there were several full-scale studies about thermal-hydraulic cases that examined the effects of the wires and pins on turbulent flow and heat transfer, which have been successfully measured by Goth et al. (2018) in the experiment. These full-scale studies involve different numbers of pins. For instance, a 19 pin-wire assemblies were studied by Liu et al. (2017) and Pacio et al. (2015). A hexagonally arrayed 37-pin wirewrapped rod bundle has been numerically studied to provide pressure loss and flow rate by Chang et al. (2016). A 61-pin wire-wrapped hexagonal fuel bundle has been performed by Chen et al. (2018). Besides, Merzari et al. (2012) studied the influence of the pin-wire contact model on thermal and hydraulical performance of the fuel bundle, and they found the CFD results are very sensitive to the selected interface model between wires and pins. Since the thermal or mechanical deformation of the structure might make the flow channels narrow, and in a consequence will affect the turbulence model used in the simulation. Thus, the choose of turbulence models is critical for performing detailed computational fluids. This poses a big challenge to the CFD calculation. In recent years, some researchers had also carried out fluid-structure coupling simulations to explain more complex phenomena under real working conditions, e.g., Dolfen et al. (2019) and Brockmeyer et al. (2020) studied the flow-induced vibration of a 7-pin wire-wrapped fuel bundle. These works provide new insights for the fluid-structure interaction simulations of the bundles.

However, to our knowledge, we have not found any full-scale finite element cases to study deformation due to contact between pins, ducts, and wires. The focus here is to find ways to resolve the complex contact between these components. In the present work, we provide a full-scale finite element model (FEM) with user defined material behavior, to study the fuel pin deformation under irradiation swelling, creep, and thermal expansion. The full scale model can accurately describe the oval deformation and wire contact dispersion.

Oval deformation and wire contact dispersion play important roles in determining the bending resistance of FBR fuels. Specifically, lateral bending of the cladding is less if the oval deformation of fuel pin is considered. Also, the lateral bending of the cladding can be alleviated by wire contact dispersion, that is, the squeezing stiffness of the bundle is smaller if the slip between wire and pin is allowed. However, these two factors are not well considered in the previous models, e.g. in BAMBOO code (Uwaba et al., 2005), the wire deviation can not vary both as a function of the axial position and peripheral position to maintain the wire-pitch; and the relationship between the contact force and ovality is considered to be linear in BAMBOO. These assumptions are not strictly valid for the real fuel pin interactions. The present work provides a full-scale model to consider these conditions for studying the bundle deformation under the working conditions with irradiation and temperature fields.

\section{Model description}

\subsection{Description of the fuel assembly}

In the present model, the fuel subassembly consists of an outer duct and 169 mixed-oxide (MOX) fuel pins. Its cross section is shown in Fig. 1(a). In order to improve the efficiency of calculation, only coresection of the bundle with large radiation dose and high temperature is considered. The length of the bundle is $L=996 \mathrm{~mm}$. In each fuel pin, the spacer wire is wrapped in the counterclockwise sense at a pitch of

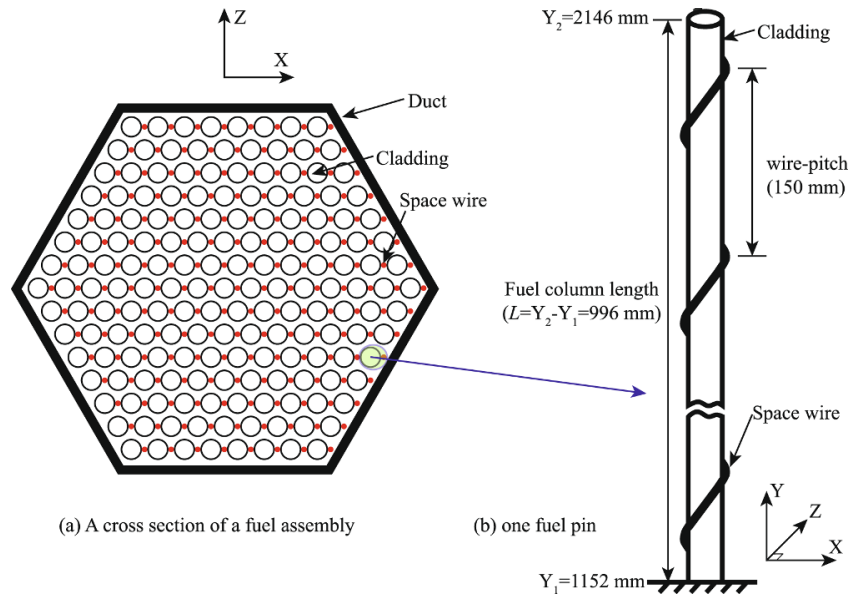

Fig. 1. The geometry of the cross section of fuel assembly and the fuel pin with its spacer wire.

$150 \mathrm{~mm}$, as schematically shown in Fig. 1(b). The relation between the wire orientation and pin axial position is the same to all fuel pins in the subassembly. The Cartesian coordinate system in 3D space is also given in Fig. 1 to facilitate the description of the results later. A general contact definition is used for the contact interactions between all components (claddings, wires and duct) in the model. The model uses a normal hard and tangential frictionless contact property for all interactions.

During the irradiation, due to the interaction of radiation swelling, thermal expansion, radiation creep and thermal creep, the fuel subassembly will undergo complex deformation (Zhao et al., 2015), which may lead to changes in the contact position and contact relationship between various components. In addition, the cladding will be contacted by some adjacent space wires due to their expansion by heating and irradiation. To accurately describe the above process, a full-scale finite element model is established in the commercial finite element package Abaqus/Explicit. The shell element (S4R) is used to simulate the claddings and the duct, and the solid element (C3D8R) is used to simulate the spacer wires. The mesh size information is as follows: the number of elements in cladding's circumference is 39 , the number of elements in wire's circumference is 16 and the mesh size in axial direction of the cladding and wire is $2.0 \mathrm{~mm}$. The visualization images of different scales of the mesh are shown in Fig. S1 of the supplementary materials. We also investigated the mesh sensitivity of the contact between the single wire and the cladding and the mesh sensitivity of the whole model. Under the above mesh size, the results are convergent. See supplementary material for details.

In view of the complex constitutive behavior of the materials, a user material subroutine VUMAT in Abaqus/Explicit was developed to accurately characterize the mechanical response of materials under irradiation and high temperature. Some researchers have implemented a similar creep constitutive model through the subroutine UMAT in the implicit FEM package Abaqus/Standard (Jian et al., 2019; Basirat et al., 2015).

Two feature planes (sections), that are the pin-duct contact plane (normal plane) and pin-wire contact plane (pinch plane), are defined to extract and interpret the results, as shown in Fig. 2. The difference between the two sections is that: In the normal plane, there is a row of wires located exactly between claddings and duct; In the pinch plane, the wires are located exactly between two adjacent claddings. There are 39 normal planes and 39 pinch planes in the entire model (6 in each wire pitch).

The structural components of these assemblies were made of modified type 316 stainless steel and $15 \mathrm{Cr}-20 \mathrm{Ni}$ base advanced austenitic stainless steel. The design parameters for a test subassembly are shown in Table 1. The test subassembly was irradiated for 558 effective full 


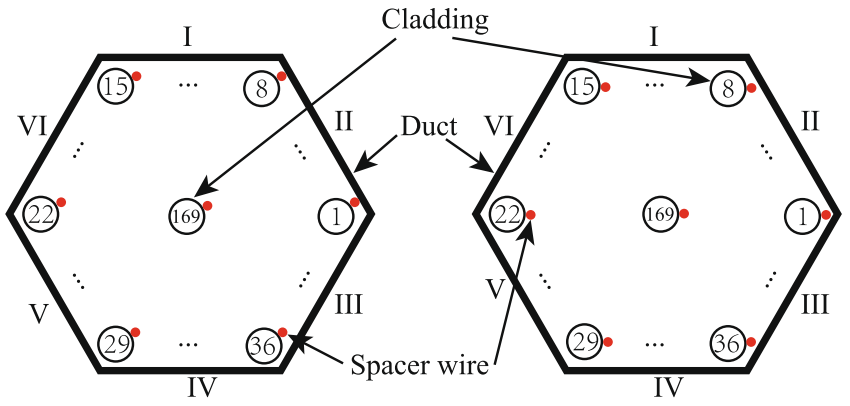

(a) Normal plane

(b) Pinch plane

Fig. 2. Schematic of two feature planes of a fuel pin bundle subassembly for the extraction of results: (a) normal plane, and (b) pinch plane.

Table 1

Design parameters for a test subassembly.

\begin{tabular}{|c|c|c|}
\hline \multicolumn{2}{|c|}{ Designed Parameters (unit) } & Value \\
\hline \multicolumn{2}{|c|}{ Number of pins } & 169 \\
\hline \multicolumn{2}{|c|}{ Fuel column length $L(\mathrm{~mm})$} & 996.0 \\
\hline & Material & $316 \mathrm{Ti} \mathrm{CW}$ \\
\hline \multirow[t]{3}{*}{ Cladding } & Outer Diameter (mm) & 6.62 \\
\hline & Wall thickness (mm) & 0.42 \\
\hline & Material & $316 \mathrm{Ti} \mathrm{CW}$ \\
\hline \multirow[t]{3}{*}{ Wire wrap } & Diameter (mm) & 1.555 \\
\hline & Axial pitch (mm) & 150.0 \\
\hline & Material & 316 Ti CW \\
\hline \multirow[t]{3}{*}{ Duct } & Wall thickness (mm) & 2.90 \\
\hline & Length of one side (mm) & 62.9 \\
\hline & Exposure (EFPDs) & 558 \\
\hline \multirow[t]{3}{*}{ Irradiation conditions } & Peak neutron fluence (dpa) & 75 \\
\hline & Peak burnup (GWd/t) & 0.65 \\
\hline & Work temperature $\left({ }^{\circ} \mathrm{C}\right)$ & 560.0 \\
\hline
\end{tabular}

power days (EFPDs). The bottom of the model $(Y=1152 \mathrm{~mm})$ was clamped (including the duct, claddings and wires). Specifically, three translational degrees of freedom (Dofs) and three rotational Dofs of the nodes at the bottom of duct and claddings (shell elements) are constrained, and three translational Dofs of the nodes at the bottom of wires (solid elements) are constrained. It should be noted that the bottom of the model is far away from the high temperature and high radiation area, and the deformation is small. It is reasonable to impose boundary conditions there. Besides, the model was warmed up and the irradiation dose was increased to simulate the near-true working conditions.

\subsubsection{Material model}

The irradiation swelling, irradiation creep, thermal creep and thermal expansion correlations of the modified type 316 stainless steel for the fuel pin bundle deformation analysis are as follows.

(1) Elastic parameters: The elastic modulus E (unit: MPa) and Poisson's ratio $\nu$ of the material vary with temperature. The relationships are as follows (Többe, 1990; Private communication with China Institute of Atomic Energy, 2019)

$$
E=195980-72.6 \cdot T
$$$$
\nu=0.29+4.41 \cdot 10^{-5} \cdot T
$$

where $T$ (unit: ${ }^{\circ} \mathrm{C}$ ) is the temperature.

(2) Irradiation swelling correlation: For the irradiation dose $d \leqslant 50 \mathrm{dpa}$, the strain of irradiation swelling strain is 0 and no special treatment is needed; and for $d>50 \mathrm{dpa}$, the following expression is given (Többe, 1990; Private communication with China Institute of Atomic Energy, 2019)
$\frac{\Delta V}{V}(\%)=0.3 \cdot \exp \left[-4.3 \cdot 10^{-5}(T-460)^{2}\right] \cdot(d-50)$

3) Irradiation creep correlation: The constitutive equations for the given creep model of claddings and wires are as follows (Chelemer et al., 1972; Uehira et al., 2000; Uwaba et al., 2011):

$\frac{\Delta \varepsilon_{e q}^{i r r}}{\sigma_{e q}}=1.1 \cdot 10^{-6} \cdot \Delta d+1.2 \cdot 10^{-2} \cdot \Delta \varepsilon^{S}$

where, $\sigma_{e q}$ is equivalent stress (unit: $\mathrm{MPa}$ ), $\Delta \varepsilon_{e q}^{i r r}$ is equivalent creep strain increment, $\Delta d$ is the increment of irradiation dose and $\Delta \varepsilon^{S}$ is irradiation swelling strain increment.

(4) Thermal creep correlation: The constitutive equations for the thermal creep model of the claddings and wires are as follows (Többe, 1990; Private communication with China Institute of Atomic Energy, 2019):

$\dot{\varepsilon}_{e q}^{\text {th }}= \begin{cases}2.017 \cdot 10^{7}\left(\sigma_{e q}\right)^{3.1} \cdot \exp \left(-\frac{Q}{T+273}\right) & \sigma_{e q} \leqslant 150 \\ 1.948 \cdot 10^{-8}\left(\sigma_{e q}\right)^{10.0} \cdot \exp \left(-\frac{Q}{T+273}\right) & \sigma_{e q}>150\end{cases}$

in which

$Q= \begin{cases}38565 & T \leqslant 700 \\ 34522+23.132 \cdot(T+273)-1.9503 \cdot 10^{-2} \cdot(T+273)^{2} & T>700\end{cases}$

where, is the equivalent thermal creep strain rate, and $Q$ is a temperature-dependent coefficient.

(5) Thermal expansion correlation: The thermal expansion coefficients $\alpha$ (unit: $1 /{ }^{\circ} \mathrm{C}$ ) of claddings and wires are the same and vary with temperature as follows (Többe, 1990; Private communication with China Institute of Atomic Energy, 2019)

$\alpha=1.867 \cdot 10^{-5}+2.5 \cdot 10^{-9}(T-20)$

\subsubsection{FEM implementation of material model: irradiation swelling as an example}

In Abaqus/Explicit, the above constitutive model is realized by writing user material subroutine VUMAT. The implementation process of each part is similar. As an example, we only consider the irradiation swelling strain when the irradiation dose $d$ is greater than $50 \mathrm{dpa}$. The strain increments caused by other mechanisms have similar updating modes. From Eq. (2), we can get the volumetric strain

$\varepsilon_{V}^{i r r a}=0.003 \cdot \exp \left[-4.3 \cdot 10^{-5}(T-460)^{2}\right] \cdot(d-50)$

The principal strains in three directions caused by irradiation swelling can be obtained from Eq. (2),

$\varepsilon_{x x}^{i r r a}=\varepsilon_{y y}^{i r r a}=\varepsilon_{z z}^{i r r a}=0.001 \cdot \exp \left[-4.3 \cdot 10^{-5}(T-460)^{2}\right] \cdot(d-50)$

The incremental expression of the irradiation swelling principal strains can be obtained by performing a variational analysis on Eq. (2),

$\Delta \varepsilon_{x x}^{i r r a}=\Delta \varepsilon_{y y}^{i r r a}=\Delta \varepsilon_{z z}^{i r r a}=0.001 \cdot \exp \left[-4.3 \cdot 10^{-5}(T-460)^{2}\right] \cdot \Delta d$

The Eq. (9) is the expression of strain increment caused by swelling and the basis for updating stress in the VUMAT of Abaqus/Explicit is:

$\Delta \varepsilon^{e}=\Delta \varepsilon-\Delta \varepsilon^{i r r a}$

$\sigma_{\text {new }}=\sigma_{\text {old }}+\Delta \sigma=\sigma_{\text {old }}+C: \Delta \varepsilon^{e}$

where, $\Delta \varepsilon^{\text {irra }}$ is the elastic strain increment and $\Delta \varepsilon$ is the total strain increment. $\sigma_{\text {old }}$ and $\sigma_{\text {new }}$ are the stress tensors corresponding to the previous incremental step and the current incremental step, respectively. $\boldsymbol{C}$ is the material stiffness matrix. $\Delta \boldsymbol{\varepsilon}^{\text {irra }}$ is the increment of thermal expansion strain tensor caused by irradiation: 


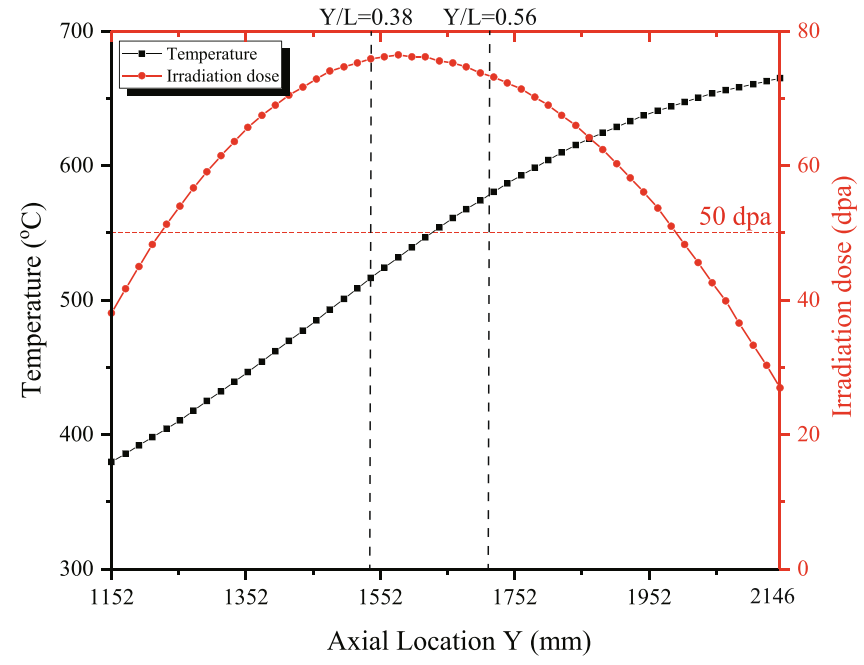

Fig. 3. Axial distribution of the coolant temperate and irradiation dose at the end (558 EFPDs). Two vertical dashed lines in the figure show the location of two typical sections $Y / L=0.38$ and $Y / L=0.56$.

$\Delta \varepsilon^{i r r a}=\left(\begin{array}{lll}\Delta \varepsilon_{x x}^{i r r a} & 0 & 0 \\ 0 & \Delta \varepsilon_{y y}^{i r r a} & 0 \\ 0 & 0 & \Delta \varepsilon_{z z}^{i r r a}\end{array}\right)$

The process of stress updating for only considering irradiation swelling effect in Abaqus/Explicit can be determined by Eq. ((9)-(12)).

\subsection{Thermal and Irradiation Conditions}

In this paper, the temperature and irradiation load are taken from real working conditions. The distributions of the temperature and irradiation dose are constant on each cross-section, but the distributions in the axial direction are different. The final distributions of the temperature and irradiation dose along the $Y$ direction are shown in Fig. 3. The loading in the simulation is as follows. The temperature was first linearly increased from $0{ }^{\circ} \mathrm{C}$ to the real working condition shown in Fig. 3. Then within 558 EFPDs, the irradiation dose was linearly increased from 0 dpa to the distribution shown in Fig. 3. In the later period of time, the temperature is kept at the real working condition.

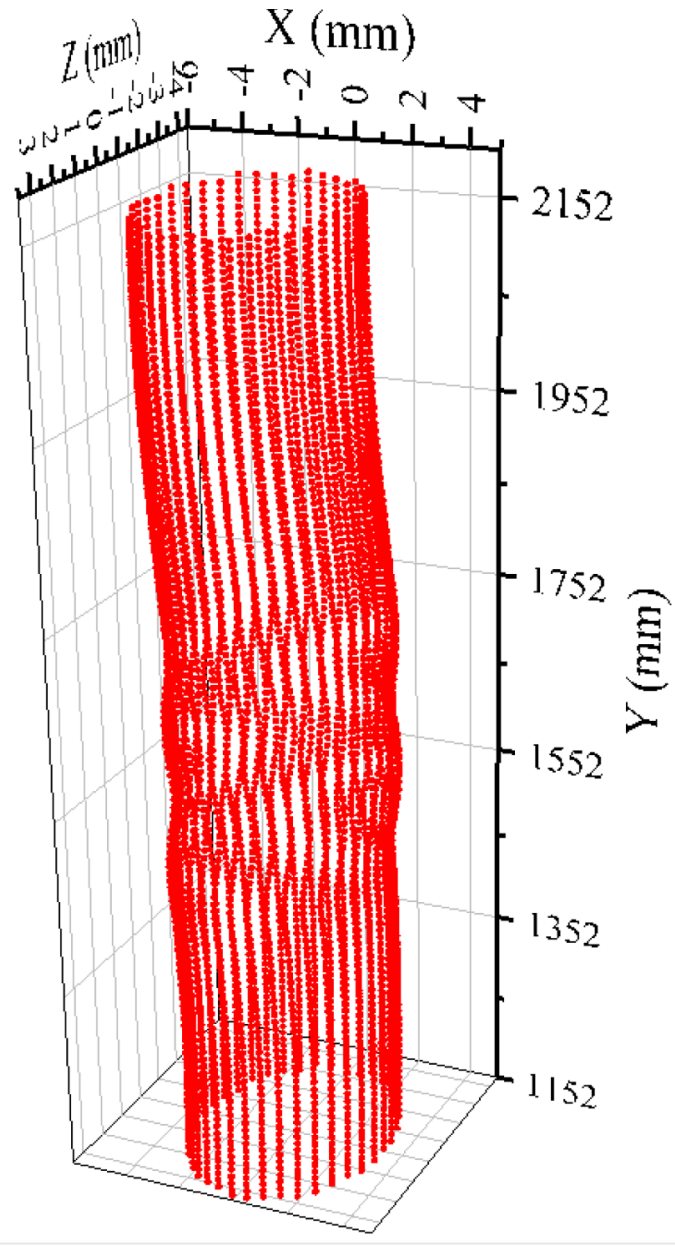

Fig. 5. The deformation diagram of the centermost cladding of fuel subassembly bundle after 558 EFPDs.

\section{Results and discussion}

\subsection{Bowing of the bundle}

The axial profile of the lateral displacement of the fuel pin array after 558 EFPDs is shown in Fig. 4, where the solid lines correspond to the lateral displaced positions and the dotted lines are their original

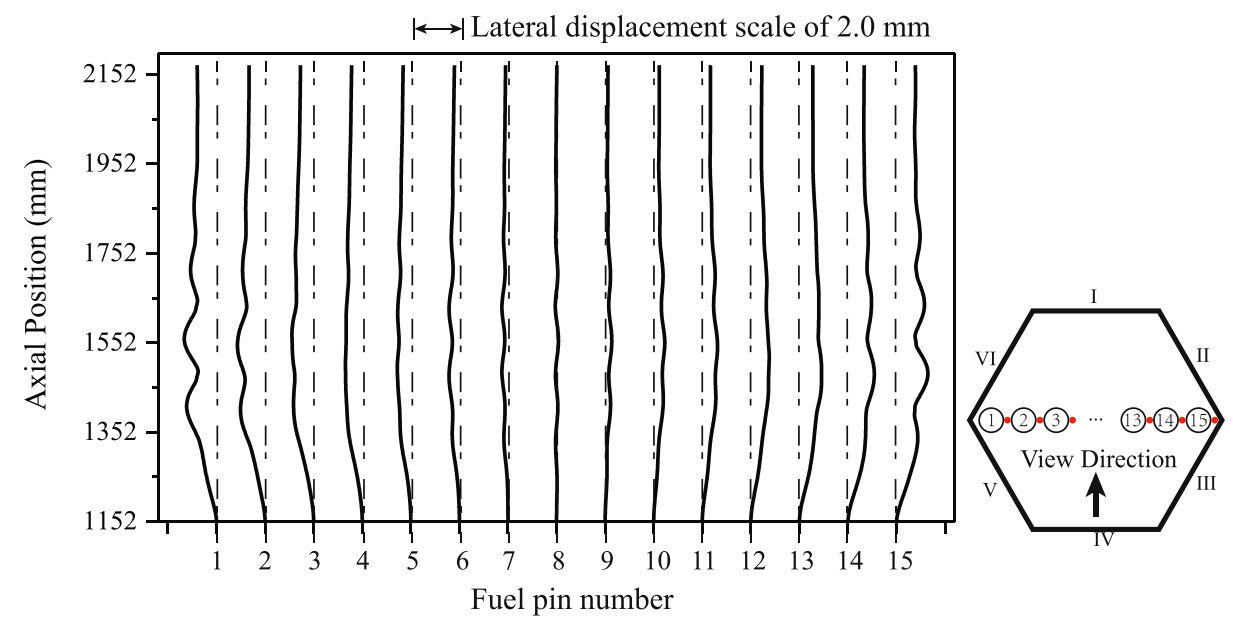

Fig. 4. Calculated lateral displacement profiles (average value of cross section) of the fuel pins in the diagonal after 558 EFPDs (The dotted lines in the figure represent the initial positions of the central axes of the claddings.). 

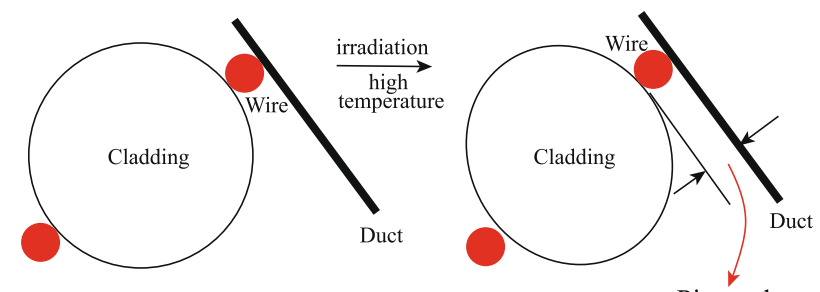

Pin-to-duct

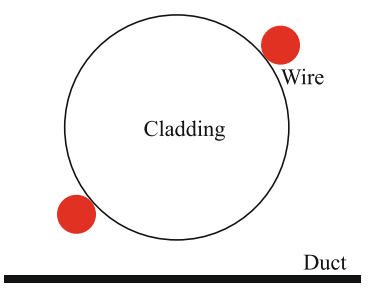

Before deformation

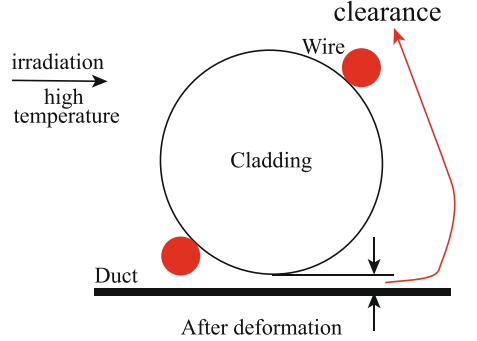

After deformation
Fig. 6. The definition diagram of the pin-to-duct clearance.

positions. Note that the average displacement of all nodes on the cross section of the cladding is given here.

From the perspective of the material model, isotropic expansion occurs at the material point. Moreover, irradiation swelling and thermal expansion are also isotropic. Under real working conditions (high irradiation dose and high temperature), irradiation swelling and thermal expansion are the two main deformation factors. The main deformation pattern of the bundle response is the transverse bending of the pins. The farther the pin is away from the center of bundle, the greater the degree of local transverse bending deformation. In addition, along the axial direction of bundle, pins have the largest local bending deformation near the locations with highest irradiation dose.

The full-scale finite element model also allows for a more accurate simulation of the cross-sectional shape of the cladding. In all simulations here, the circumferential direction of the cladding is divided into 39 elements (the edge length of the element is $0.53 \mathrm{~mm}$ ). The deformation diagram of the centermost cladding of fuel-subassembly bundle after 558 EFPDs of high temperature and irradiation is shown in Fig. 5, where the local deformation of the cladding details can be observed. We can clearly see the restrained "traces" of the expansion of the cladding caused by spacer wire, especially at the location with high temperature and irradiation (from $Y=1352 \mathrm{~mm}$ to $Y=1752 \mathrm{~mm}$ ).

\subsection{Pin-to-duct clearance and oval distortion}

Pin-to-duct clearance is often used to quantitatively evaluate the blockage of flow channels in fuel bundles. For a certain section of an assembly, pin-to-duct clearance is defined as the distance from the duct to the nearest points on the section of the cladding. An intuitive definition of the pin-to-duct clearance is shown in Fig. 6. The figure shows the deformation of two typical contact between cladding and duct, as well as the definition of pin-to-duct clearance.

The peripheral distribution of the pin-to-duct clearances of different cross sections $(Y / L=0.38$ and $Y / L=0.56)$ are shown in Figs. 7 and 8. These two sections are both normal planes. The positions of the spacer wires for the bundle peripheral pins in the bundle are shown on the right-side of Figs. 7 and 8.

As can be seen from Fig. 7 and Fig. 8, for the case of $Y / L=0.38$, the pin-to-duct clearance of the plane I is larger, while that of the plane IV (opposite to plane I) is smaller. Near plane I, the spacer wires are directed toward the plane. These wires prevent the cladding from bending toward the plane. Therefore, the pin-to-duct clearance in plane I is relatively large. On the other hand, near plane IV, the spacer wires are opposite to the duct, so the pin can easily move to plane IV. In this case, the pin-to-duct clearance is relatively small. Similar results were obtained for the case of $Y / L=0.56$ (the pin-to-duct clearance of plane VI was larger than that of plane III). Besides, we also noticed that the minimum pin-to-duct clearance of $Y / L=0.38$ was much smaller than that of $Y / L=0.56$, which was due to the larger radiation dose and radiation expansion deformation at $Y / L=0.38$.

The minimum pin-to-duct clearance as a function of the axial position is shown in Fig. 9. The smallest value of minimum pin-to-duct clearance and the largest pin deformation are near the middle of the bundle (at the position of $Y / L=0.36$ ), this is because the distribution of irradiation dose along the bundle axis is high in the middle and low in the two ends. The minimum pin-to-duct clearance along the axis of the bundle, as shown in Fig. 9, indicates that a narrow channel (with clearance about $0.6 \mathrm{~mm}$ ) occurs at the position of $Y / L=0.38$. The decrease of clearance (around 60\%) reduces the flow rate of the fluid for heat exchange. Less cooling of fluid can cause local overheating, leading to larger pin deformation and narrower flow channel.

Because of the expansion of the spacer wires, the cladding is compacted and the cross section shape of the cladding changes. The comparison of the shape of the middle row of cladding before and after deformation at $Y / L=0.546$ (pinch plane) is shown in Fig. 10. Here, we translate the initial configuration so that its center coincides with the

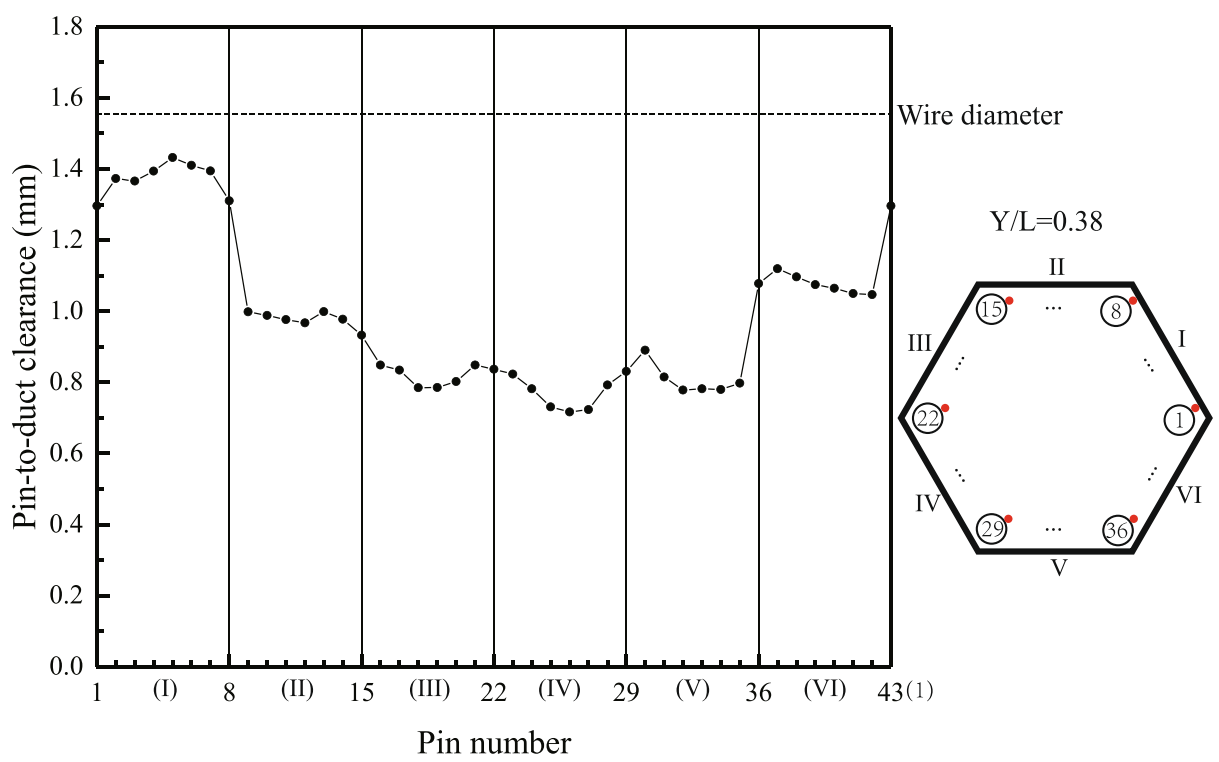

Fig. 7. Peripheral distribution of the pin-to-duct clearance at the section of $Y / L=0.38$ (normal plane). 


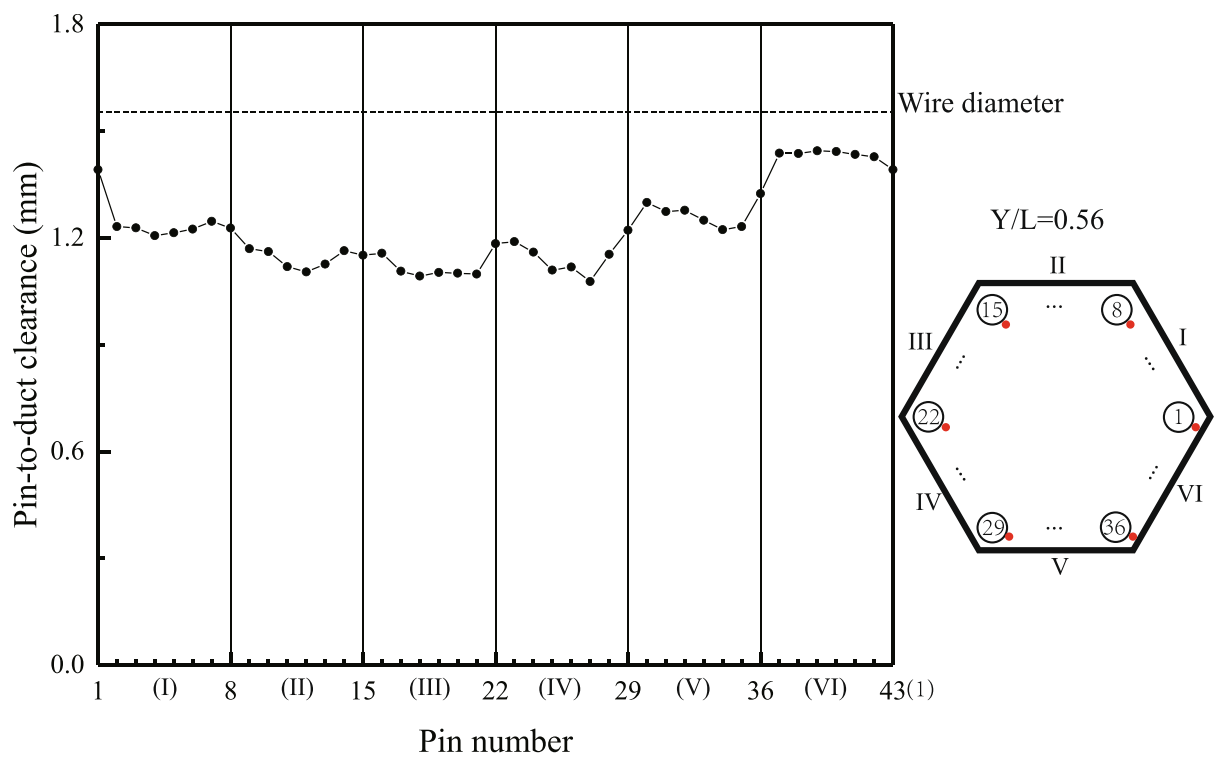

Fig. 8. Peripheral distribution of the pin-to-duct clearance at the section of $Y / L=0.56$ (normal plane).

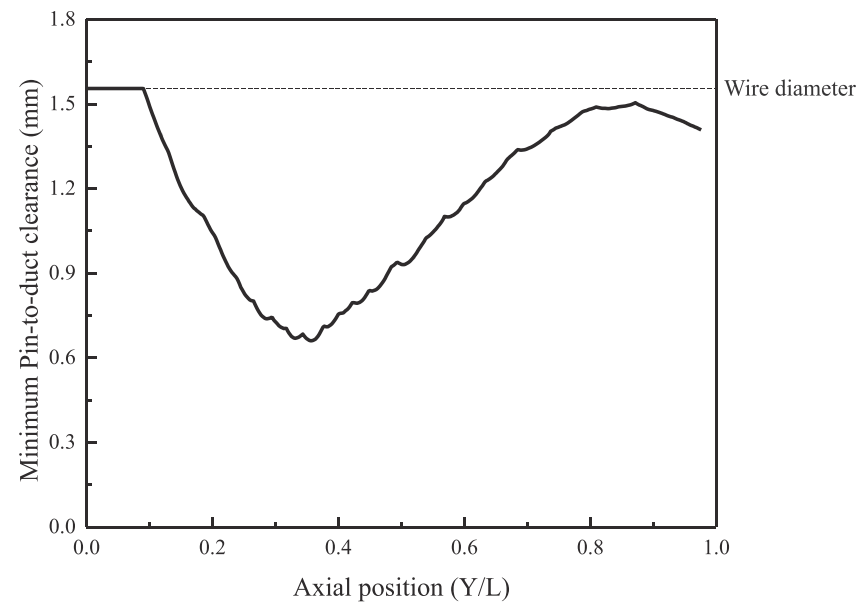

Fig. 9. Minimum pin-to-duct clearances along the axis of the bundle (the abscissa is the axial position made dimensionless with the bundle's length). center of the deformed configuration, for better observation of the shape change of the cladding. Note that the penetration of claddings 1 and 2 in Fig. 10 is caused by deformation amplification, and no penetration occurs under real deformation. As can be seen from the figure, cladding has changed from a circular shape to a oval-shaped one. It can be approximately considered that the deformed configuration is an ellipse. Further, from the relative position between the deformed position of each cladding and the horizontal dashed line in Fig. 10, different degrees of the claddings' deformation along $Z$ direction can be observed. We also give a schematic diagram of a typical cladding section changing from circular to oval under working conditions, as shown in Fig. 11. It can be seen that the oval deformation of the cladding is mainly caused by the compression of the adjacent wires.

In order to quantitatively characterize the oval deformation of the claddings and the dispersion along $\mathrm{Z}$ direction, we draw the ovality distributions and the Z-direction displacement distributions of the middle row of the claddings at a pinch plane $(Y / L=0.546)$ and a normal plane $(Y / L=0.560)$, respectively, as shown in Fig. 12 and Fig. 13. Here, the ovality $\Delta D$ is defined as follows:

$\Delta D=D_{f}-D_{n}$

where $D_{f}$ and $D_{n}$ are the distances between the farthest two points and

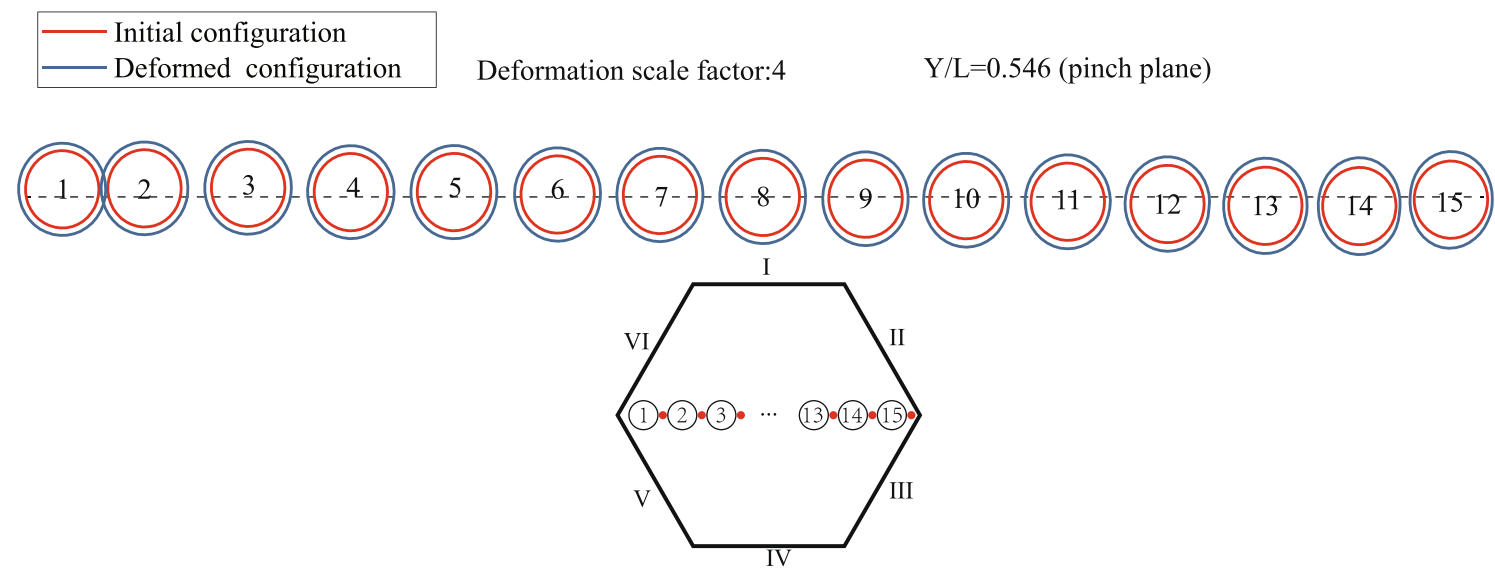

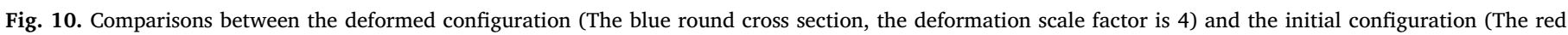

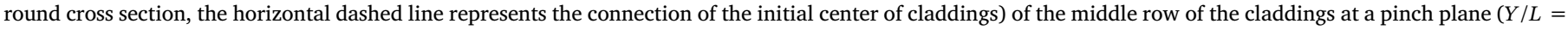
0.546). (For interpretation of the references to colour in this figure legend, the reader is referred to the web version of this article.) 


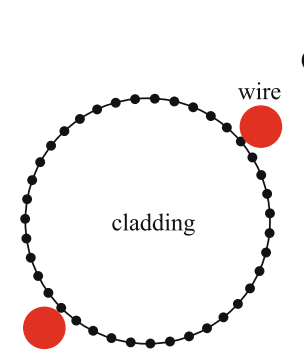

(a) Before deformation

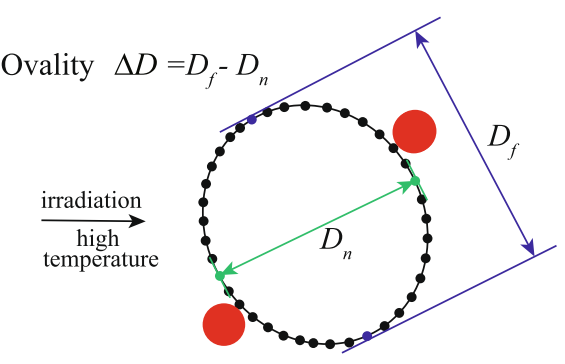

(b) After deformation
Fig. 11. The schematic diagram of oval deformation of cladding and the definition of the ovality.

the nearest two points among the 39 nodes of a certain section of a cladding, respectively. More detailed and intuitive definitions of $D_{f}$ and $D_{n}$, as well as ovality are also shown in Fig. 11.

The oval deformations of the middle row of the claddings at a pinch plane $(Y / L=0.546)$ and a normal plane $(Y / L=0.560)$ accumulates continuously from left to right, reaching a maximum of $0.23 \mathrm{~mm}$
$(Y / L=0.546)$ and $0.09 \mathrm{~mm}(Y / L=0.560)$ near the outer duct on the right side, respectively. We also notice that the ovality in the pinch plane is greater than that in the normal plane near it. This is because, in the section of the pinch plane, the wires are located exactly between two adjacent claddings. Under compressive load, a large oval deformation will occur. In addition, the Z-direction deviation distributions indicate that they are no longer in the middle, but have some degree of misalignment and adjustment for both normal plane and pinch plane.

\subsection{Dispersion of the wire-cladding contact}

Under irradiation, the fuel pin arrangement of the bundle may be displaced due to thermal and irradiation effects. This phenomenon is called pin dispersion. From the mechanical point of view, the dispersion of fuel pin may be caused by the change of contact position with spacer wire. Our full-scale finite element model can naturally simulate the contact, separation and slip of the cladding and wire, so as to analyze the dispersion process and quantitatively express the degree of dispersion.

The contact state between the middle row of claddings and the
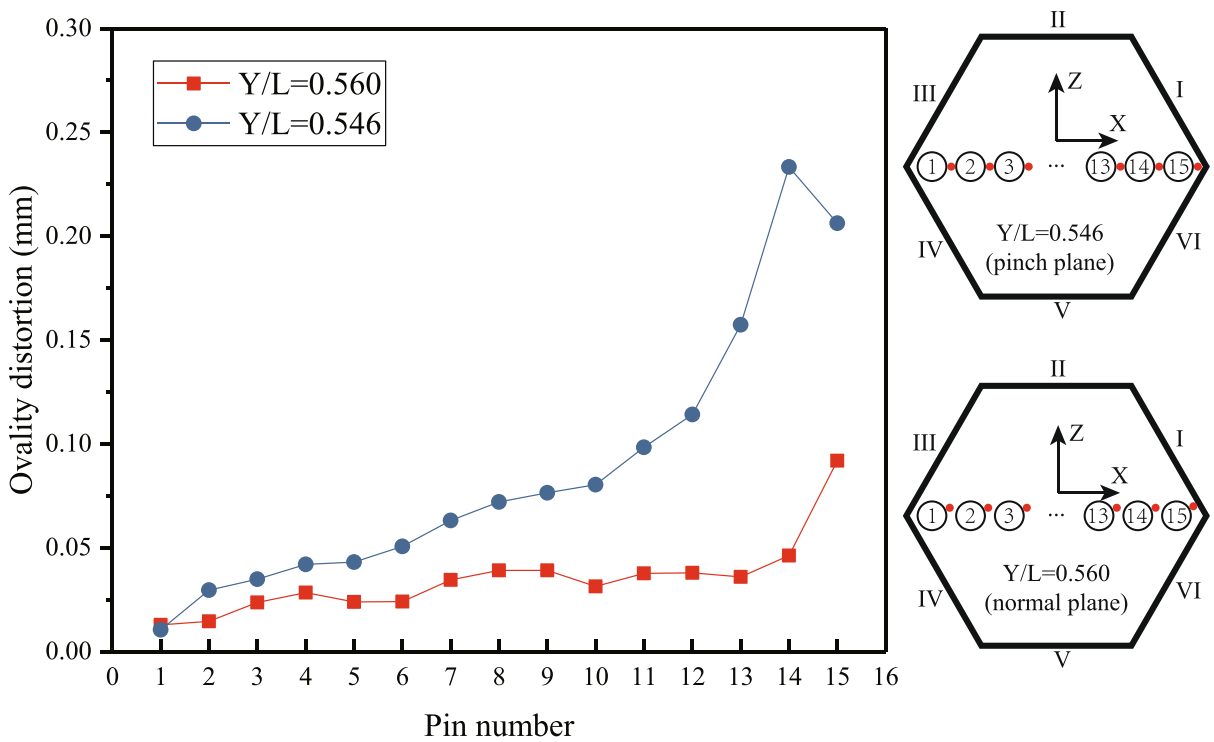

Pin number

Fig. 12. The ovality distributions of claddings in the middle row at a pinch plane $(Y / L=0.546)$ and a normal plane $(Y / L=0.56)$.
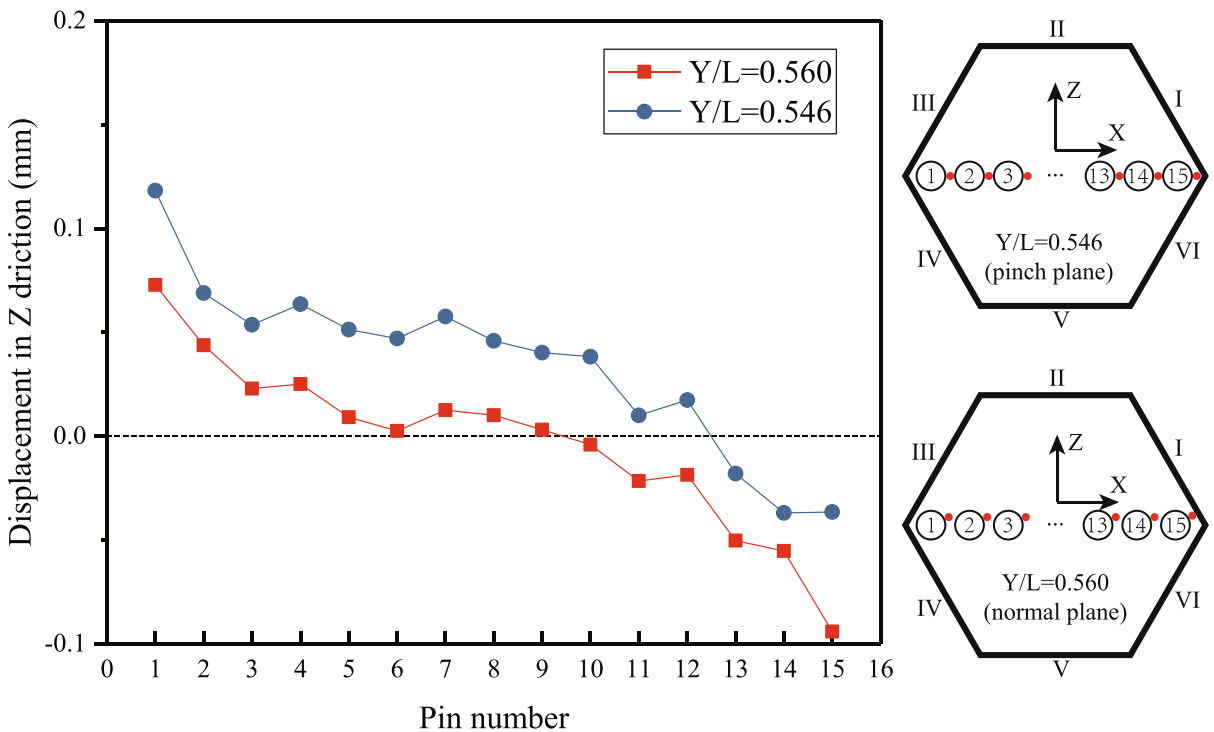

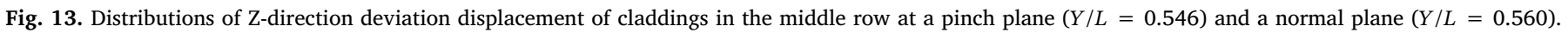




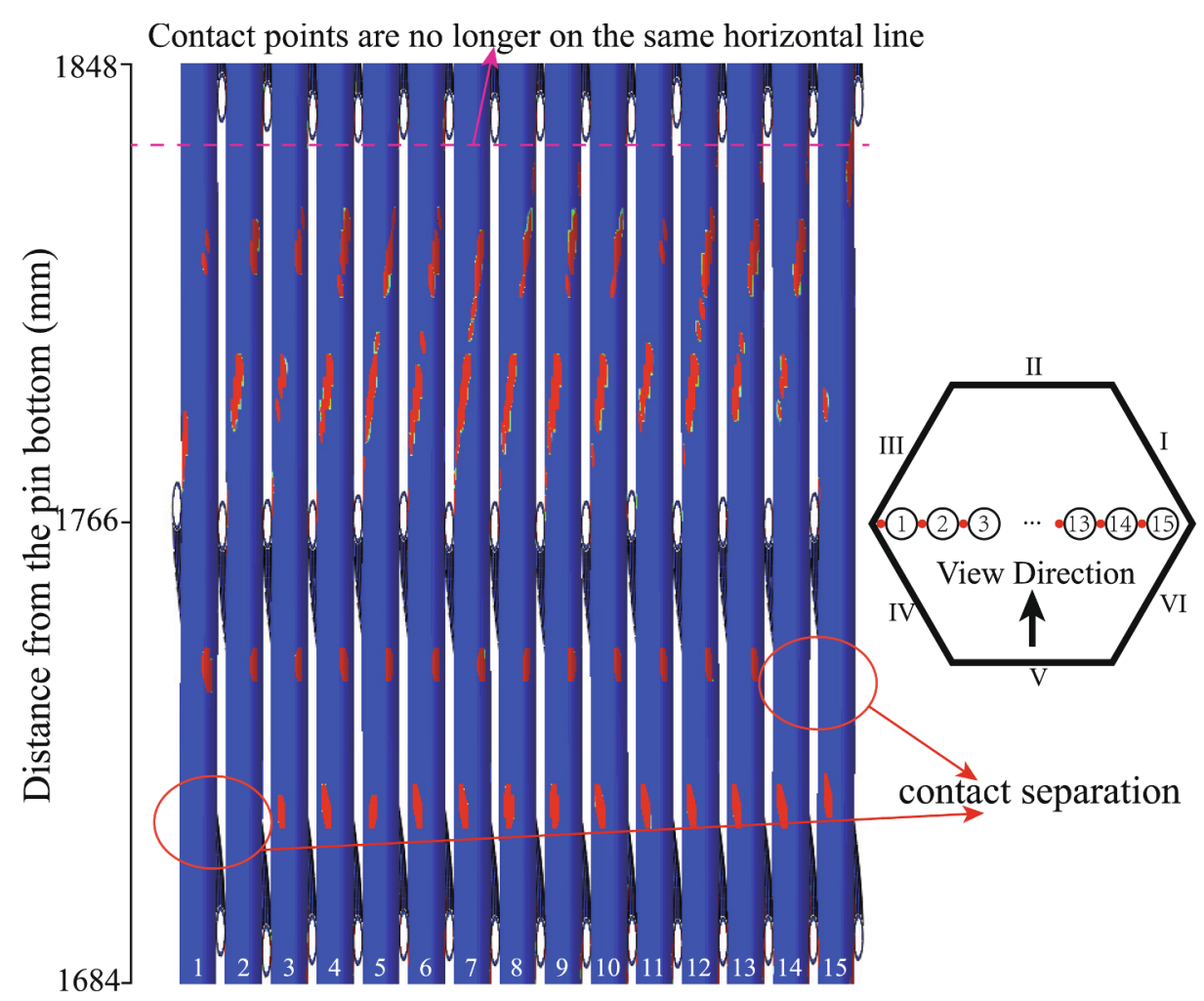

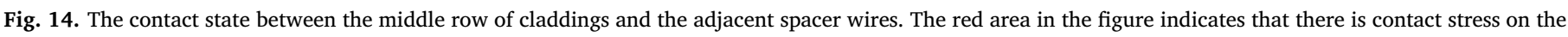
claddings. (For interpretation of the references to colour in this figure legend, the reader is referred to the web version of this article.)

adjacent spacer wires is given in Fig. 14 (The height direction $(Y$ direction) in the graph is only partially intercepted (from $Y=1684 \mathrm{~mm}$ to $Y=1848 \mathrm{~mm}$ )). Contact separation may occur between the cladding and the spacer wire near the duct, that is, there will be no contact at the initial contacted position after operation. The original contact points of the same initial height do not remain at the same height after deformation, but are dispersed.

Fig. 15 shows the Mises stress distribution and contact state before and after the deformation of the cladding and the spacer wire of the centermost pin. Initially, there was always a line contact along the
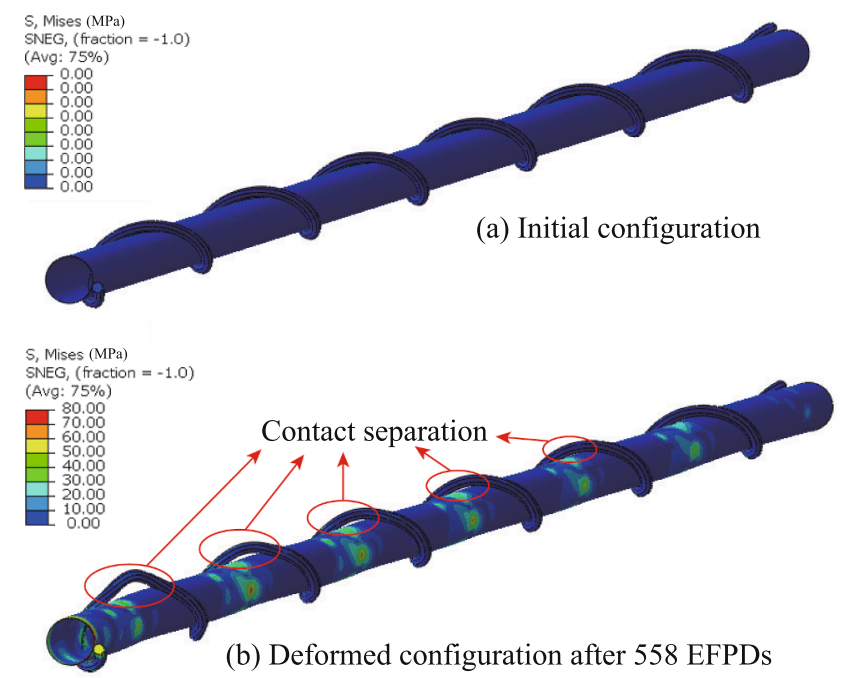

Fig. 15. The initial configuration and the deformed configuration of the centermost pin and the spacer wire (the viewing angle is adjusted to magnify the local effect). cladding's axis. After 558 EPFDs, some of these contacts have separated, while others have become closer (from point-to-point contact to face-toface contact). The closer to the top of the bundle (free end), the greater the degree of contact separation. This is because at the near free end of the bundle, the bundle has less restriction on the inner wires and claddings. As a result of different thermal and irradiative material models, the wires and claddings near the free end of the bundle (referring to the free end along the axial direction) will be out of the duct. The extruded parts are no longer constrained by the duct, thus are easier to deform.

\subsection{Effect of working conditions on bundle deformation}

Because the irradiation swelling has an important influence on the bending deformation and safety of the bundle structure, the deformation response of the bundle structure under different working conditions (especially under different irradiation intensities) needs to be studied.

The lateral displacement profiles of the middle row of claddings at three different irradiation intensities ( $d=65 \mathrm{dpa}, 75 \mathrm{dpa}$ and $100 \mathrm{dpa})$ are shown in Fig. 16. As the irradiation intensity increases, the bending deformation of the cladding increases. When $d=100 \mathrm{dpa}$, the bending degree of the cladding is much larger than that of $d=65 \mathrm{dpa}$ and 75 dpa (the maximum lateral displacement is about twice that of $d=75$ dpa), mainly because the radiation swelling only works when $d>50$ dpa.

The peripheral distribution of the pin-to-duct clearance at the section of $Y / L=0.38$ at 558 EFPDs under three different irradiation intensities $(d=65 \mathrm{dpa}, 75 \mathrm{dpa}$ and $100 \mathrm{dpa})$ is given in Fig. 17. Similarly, the pin-to-duct clearance decreases as the irradiation dose increase. At the same time, we also noticed that when $d=100 \mathrm{dpa}$, some of the claddings are in contact with the duct, that is, the values of the pin-to-duct clearance are zero. This is a very dangerous situation, which can cause fluid blockage and local overheating in the bundle. Additional attention and monitoring are required in the design and operation of the bundle. 


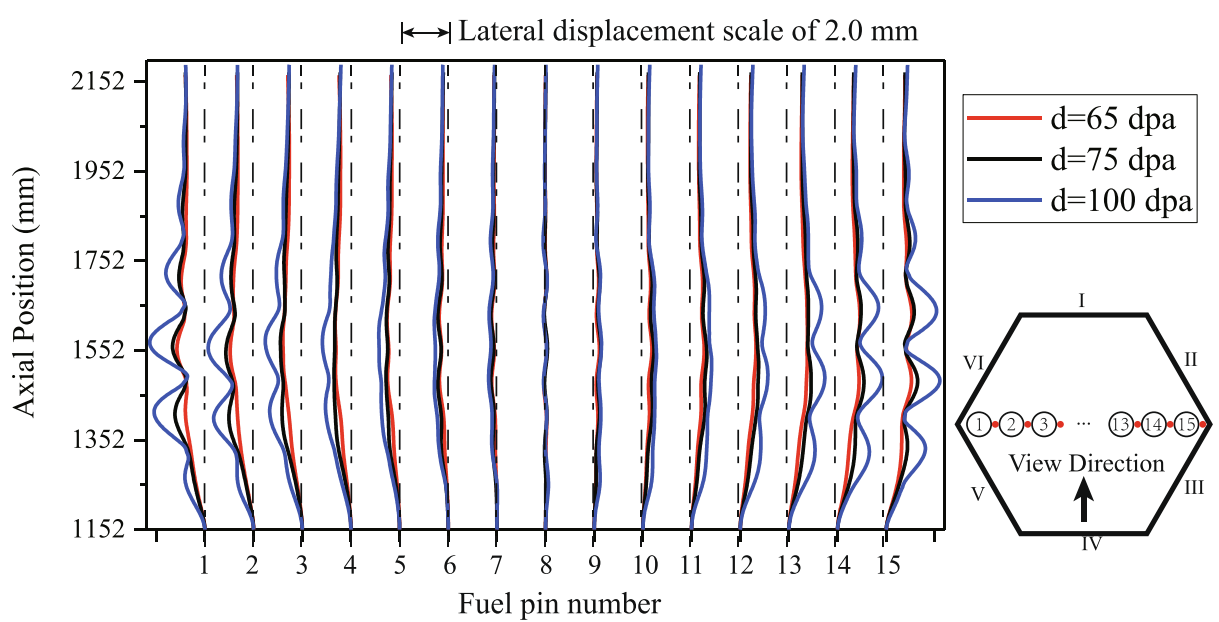

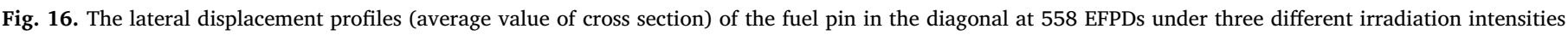
( $d=65 \mathrm{dpa}, 75 \mathrm{dpa}$ and $100 \mathrm{dpa}$ ). The dotted lines in the figure represent the initial positions of the central axis of the claddings.

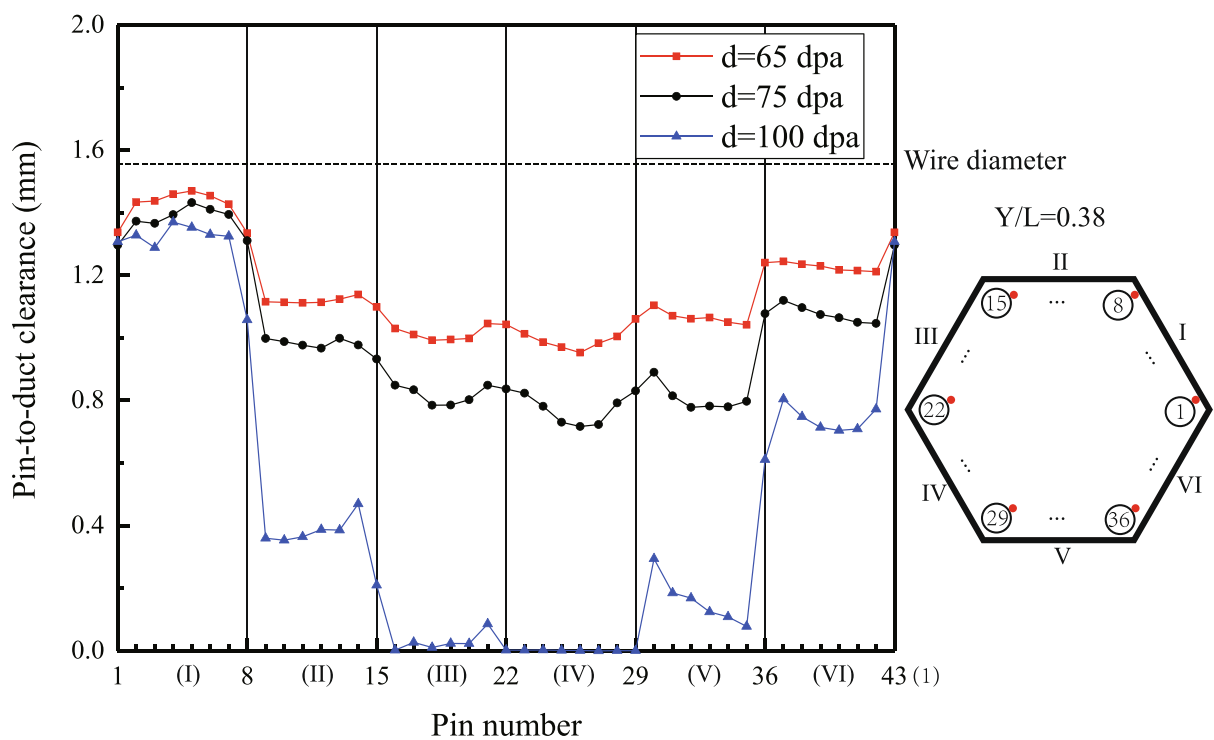

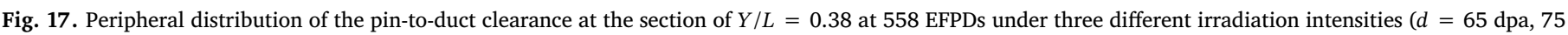
dpa and $100 \mathrm{dpa})$.

\section{Discussion}

BAMBOO calculated the deformation of pin-bundle by two steps: the oval stiffness is experimentally obtained by compression test of a single wire-wrapped pin, the obtained stiffness is used for the spring element to represent the wire-contacts between adjacent pins; deformation of pin-bundle, including pin's bowing and cladding's oval distortion, is calculated by using 3D beam element for the pin and the spring element for the contact. While in our model, the oval deformation is naturally coupled with the pin bending, so that the nonlinear effect from contact-change can be considered during the deformation. The axial dispersion, as well as peripheral dispersion, can be taken into account in present model to produce accurate prediction of pin-to-duct clearance. For instance, as in Fig. 7, pin-to-duct clearance of pins 1 to 8, calculated by BAMBOO, is always the diameter of wire, because BAMBOO does not consider peripheral dispersion. With considering peripheral dispersion in our model, we found out that pin-to-duct clearance is approximate 10 percent less than the wire diameter with present boundary conditions. In the similar position as pins 1 to 8 in Fig. 7, the differences of pin-to-duct clearance between BAMBOO calculation and out-of-pile bundle test was observed in the work (Uwaba et al., 2014), the peripheral dispersion is a key factor for the difference.

\section{Conclusions}

In this paper, we developed a full-scale finite element model to simulate the complex contact behavior of the wire-wrapped fuel subassembly during operation condition. Constitutive behavior of the bundle subassembly, considering thermal expansion, thermal creep, irradiation swelling, and irradiation creep, is realized by user subroutine in the commercial finite element software package Abaqus/ Explicit. With the contact (between the duct, pins, and wires) well solved by the explicit solver, the full-scale model can accurately predict the bundle deformation under operation. Under the combined effects of radiation swelling and radiation creep, the contact position and state between wires and cladding may change in three aspects: a dispersion of contact points along the height direction, a dispersion of contact points along the peripheral direction, and the switch of contact state either from contact to separation or vice versa. With the developed model, we find out that the latter two new aspects, which has not been discovered in all previous studies, also pay an important role for alleviating the severe transverse bending of the bundle. The observed new 
mechanism - contact peripheral dispersion and separation - can provide a new perspective on the design of bundles.

\section{CRediT authorship contribution statement}

X. Ye: Methodology, Writing - original draft. F. Gao: Formal analysis, Investigation, Resources. X. Chen: Validation, Software. X. Liu: Conceptualization, Writing - review \& editing, Supervision. Y.G. Wei: Supervision.

\section{Declaration of Competing Interest}

The authors declare that they have no known competing financial interests or personal relationships that could have appeared to influence the work reported in this paper.

\section{Acknowledgment}

This work was supported by the National Natural Science Foundation of China (No. 11772334, 11672301) and by Youth Innovation Promotion Association CAS (2018022), and by the Strategic Priority Research Program of the Chinese Academy of Sciences (No. XDB22040501).

\section{Appendix A. Supplementary data}

Supplementary data associated with this article can be found, in the online version, athttps://doi.org/10.1016/j.nucengdes.2020.110676.

\section{References}

Basirat, M., Shrestha, T., Barannyk, L.L., Potirniche, G.P., Charit, I., 2015. A creep damage model for high-temperature deformation and failure of $9 \mathrm{cr}-1 \mathrm{mo}$ steel weldments. Metals 5 (3), 1487-1506. https://doi.org/10.3390/met5031487. URL https://www. mdpi.com/2075-4701/5/3/1487.

Brockmeyer, L., Merzari, E., Solberg, J., Hassan, Y., 2020. One-way coupled simulation of FIV in a 7-pin wire-wrapped fuel pin bundle. Nucl. Eng. Des. 356, 110367. https:// doi.org/10.1016/j.nucengdes.2019.110367. URL http://www.sciencedirect.com/ science/article/pii/S002954931930398X.

Chang, S.-K., Euh, D.-J., Choi, H.S., Kim, H., Choi, S.R., Lee, H.-Y., 2016. Flow distribution and pressure loss in subchannels of a wire-wrapped 37-pin rod bundle for a sodiumcooled fast reactor. Nucl. Eng. Technol. 48 (2), 376-385. https://doi.org/10.1016/j. net.2015.12.013. URL http://www.sciencedirect.com/science/article/pii/ S1738573316000127.

Chelemer, H., Weisman, J., Tong, L.S., 1972. Subchannel thermal analysis of rod bundle cores. Nucl. Eng. Des. 21 (1), 35-45. https://doi.org/10.1016/0029-5493(72)900842. URL http://www.sciencedirect.com/science/article/pii/0029549372900842.

Chen, J., Zhang, D., Song, P., Wang, X., Wang, S., Liang, Y., Qiu, S., Zhang, Y., Wang, M., Su, G.H., 2018. CFD investigation on thermal-hydraulic behaviors of a wire-wrapped fuel subassembly for sodium-cooled fast reactor. Ann. Nucl. Energy 113, 256-269. https://doi.org/10.1016/j.anucene.2017.11.023. URL http://www.sciencedirect. com/science/article/pii/S0306454917304048.

Dolfen, H., Bertocchi, F., Rohde, M., Degroote, J., 2019. Vibrations in a 7-rod bundle subject to axial flow: Simulations and experiments. Nucl. Eng. Des. 353, 110227. https://doi.org/10.1016/j.nucengdes.2019.110227. URL http://www.sciencedirect. com/science/article/pii/S002954931930247X

Goth, N., Jones, P., Duy Nguyen, T., Vaghetto, R., Hassan, Y., Salpeter, N., Merzari, E., 2018. PTV/PIV measurements of turbulent flows in interior subchannels of a 61-pin wire-wrapped hexagonal fuel bundle. Int. J. Heat Fluid Flow 71, 295-304. https:// doi.org/10.1016/j.ijheatfluidflow.2018.03.021.

Itoh, K., Kinjo, H., Mimura, Y., 1994. Development of a 3-D FBR fuel bundle-to-duct interaction analysis code marse. Nucl. Eng. Des. 148 (1), 53-69. https://doi.org/10. 1016/0029-5493(94)90241-0. URL http://www.sciencedirect.com/science/article/ pii/0029549394902410.

Jian, X., Yan, F., Kong, X., Ding, S., 2019. Effects of u-mo irradiation creep coefficient on the mesoscale mechanical behavior in u-mo/al monolithic fuel plates. Nucl. Mater.
Energy 21, 100706. https://doi.org/10.1016/j.nme.2019.100706. URL http://www. sciencedirect.com/science/article/pii/S2352179119300511.

Liu, L., Wang, S., Bai, B., 2017. Thermal-hydraulic comparisons of 19-pin rod bundles with four circular and trapezoid shaped wire wraps. Nucl. Eng. Des. 318, 213-230. https://doi.org/10.1016/j.nucengdes.2017.04.017. URL http://www.sciencedirect. com/science/article/pii/S0029549317301784.

Maeda, K., Katsuyama, K., Asaga, T., 2005. Fission gas release in FBR MOX fuel irradiated to high burnup. J. Nucl. Mater. 346 (2), 244-252. https://doi.org/10.1016/j. jnucmat.2005.06.014. URL http://www.sciencedirect.com/science/article/pii/ S0022311505003053.

Merzari, E., Pointer, W.D., Smith, J.G., Tentner, A., Fischer, P., 2012. Numerical simulation of the flow in wire-wrapped pin bundles: effect of pin-wire contact modeling. Nucl. Eng. Des. 253, 374-386. https://doi.org/10.1016/j.nucengdes.2011.09.030. URL http://www.sciencedirect.com/science/article/pii/S0029549311008235.

Pacio, J., Litfin, K., Batta, A., Viellieber, M., Class, A., Doolaard, H., Roelofs, F., Manservisi, S., Menghini, F., Böttcher, M., 2015. Heat transfer to liquid metals in a hexagonal rod bundle with grid spacers: experimental and simulation results. Nucl. Eng. Des. 290, 27-39. https://doi.org/10.1016/j.nucengdes.2014.11.001. URL http://www.sciencedirect.com/science/article/pii/S0029549314005779.

Private communication with China Institute of Atomic Energy, 2019.

Sakai, K., Okubo, Y., Hishida, H., 1978. Three-dimensional deflection analyses of wirespaced fuel pin bundles under temperature and hydrodynamic force fields with irradiation effects. Nucl. Eng. Des. 48 (2), 595-610. https://doi.org/10.1016/0029. 5493(78)90101-2. URL http://www.sciencedirect.com/science/article/pii/ 0029549378901012 .

Shan, J., Zhang, B., Li, C., Leung, L.K.H., 2009. SCWR subchannel code ATHAS development and CANDU-SCWR analysis. Nucl. Eng. Des. 239 (10), 1979-1987. https:// doi.org/10.1016/j.nucengdes.2009.05.008. URL http://www.sciencedirect.com/ science/article/pii/S0029549309002301.

Shibahara, I., Ukai, S., Onose, S., Shikakura, S., 1993. Irradiation performance of modified 316 stainless steel for Monju fuel. J. Nucl. Mater. 204, 131-140. https://doi.org/ 10.1016/0022-3115(93)90209-H. URL http://www.sciencedirect.com/science/ article/pii/002231159390209H.

Sun, R.L., Zhang, D.L., Liang, Y., Wang, M.J., Tian, W.X., Qiu, S.Z., Su, G.H., 2018. Development of a subchannel analysis code for SFR wire-wrapped fuel assemblies. Prog. Nucl. Energy 104, 327-341. https://doi.org/10.1016/j.pnucene.2017.12.005. URL http://www.sciencedirect.com/science/article/pii/S0149197017303050.

H. Többe, IAMBUS - A computer code for the design and performance prediction of fast breeder fuel rods, Technical Report, DE03FH121, Bergisch Gladbach 1, May. (1990).

Uehira, A., Mizuta, S., Ukai, S., Puigh, R.J., 2000. Irradiation creep of $11 \mathrm{cr}-0.5 \mathrm{mo}-2 \mathrm{w}, \mathrm{V}$, $\mathrm{Nb}$ ferritic-martensitic, modified 316, and 15cr-20ni austenitic S.S. irradiated in FFTF to 103-206 dpa. J. Nucl. Mater. 283-287 (1), 396-399. https://doi.org/10. 1016/S0022-3115(00)00079-9. URL http://www.sciencedirect.com/science/article/ $\mathrm{pii} / \mathrm{S} 0022311500000799$.

Uwaba, T., Tanaka, K., 2001. Development of a Fast breeder reactor fuel bundle-duct interaction analysis code-BAMBOO: analysis model and validation by the out-of-pile compression test. Nucl. Technol. 136 (1), 14-23. https://doi.org/10.13182/NT01 A3225.

Uwaba, T., Ito, M., Ukai, S., 2004. Development of a Fast breeder reactor fuel bundle deformation analysis code - BAMBOO: development of a pin dispersion model and verification by the out-of-pile compression test. Nucl. Technol. 145 (2), 230-237. https://doi.org/10.13182/NT04-A3472.

Uwaba, T., Ito, M., Ukai, S., Pelletier, M., 2005. Development of a FBR Fuel Bundle-duct Interaction Analysis Code-BAMBOO. J. Nucl. Sci. Technol. 42 (7), 608-617. https:// doi.org/10.1080/18811248.2004.9726428.

Uwaba, T., Ito, M., Maeda, K., 2011. Diametral strain of fast reactor MOX fuel pins with austenitic stainless steel cladding irradiated to high burnup. J. Nucl. Mater. 416 (3), 350-357. https://doi.org/10.1016/j.jnucmat.2011.06.033. URL http://www. sciencedirect.com/science/article/pii/S0022311511005976.

Uwaba, T., Ito, M., Nemoto, J., Ichikawa, S., Katsuyama, K., 2014. Verification of the FBR fuel bundle-duct interaction analysis code BAMBOO by the out-of-pile bundle compression test with large diameter pins. J. Nucl. Mater. 452 (1), 552-556. https://doi. org/10.1016/j.jnucmat.2014.06.016. URL http://www.sciencedirect.com/science/ article/pii/S0022311514003730.

Uwaba, T., Ohshima, H., Ito, M., 2017. Analyses of deformation and thermal-hydraulics within a wire-wrapped fuel subassembly in a liquid metal fast reactor by the coupled code system. Nucl. Eng. Des. 317, 133-145. https://doi.org/10.1016/j.nucengdes. 2017.03.026. URL http://www.sciencedirect.com/science/article/pii/ S0029549317301395.

Zhao, Y., Gong, X., Ding, S., 2015. Simulation of the irradiation-induced thermo-mechanical behaviors evolution in monolithic u-mo/zr fuel plates under a heterogeneous irradiation condition. Nucl. Eng. Des. 285, 84-97. https://doi.org/10.1016/ j.nucengdes.2014.12.030. URL http://www.sciencedirect.com/science/article/pii/ S0029549315000199. 